\title{
Phenotyping the Clotting System
}

\author{
H. Coenraad Hemker, Suzette Béguin
}

From Synapse b. v. and the Department of Biochemistry, Cardiovascular Research Institute (CARIM) Maastricht, The Netherlands

The combined research efforts in our field over the last hundred years made that we now recognise dozens of plasma proteins with a function in the clotting system and a set of platelet components that is of the same order. Progress in molecular biology is such as to have identified some one hundred genes that may influence haemostasis and thrombosis and a new one comes about every month. Nevertheless the phenotype of the clotting system cannot be adequately established. There is no simple method that gives us a clear picture of the net result of the activity of all those genes, together with non-genetic influences (e.g. drugs), on the over-all clotting function of blood at a given moment.

For over a century we make do with clotting times that we know to be marginally - if at all - sensitive to hypercoagulability and mild bleeding disorders. We are used to employing different variants for the control of oral anticoagulants and of heparin. Some anticoagulants do not significantly influence any type of clotting time and for convenience are assumed not to require control. Standardisation is a constant problem. But we are so used to clotting times as to almost forget that they do not actually serve the purpose of a simple adequate indicator of clotting function, that we lack a test that is equivalent to blood sugar in diabetes or blood pressure in hypertension.

Conceivably measuring thrombin generation could be such a test. Thrombin is at a focal point in haemostasis and thrombosis. The whole "clotting" mechanism is engaged in its generation and subsequent inactivation. During its active life it exerts a multitude of actions on the blood and the vessel wall, among which the clotting of fibrinogen. The sum of these actions is haemostatic and/or thrombotic. The part played by thrombin has always been evident in haemophiliac bleeding and venous thrombosis. It becomes more and more clear that it is also pivotal in arterial thrombosis (1-4). Anticoagulant therapies that decrease thrombin formation by completely different mechanisms, such as oral anticoagulation and heparin, are effective in both venous and arterial thrombosis $(5,6)$. Even "antiplatelet" drugs do influence thrombin generation (see below).

\section{The Consequences of Complication}

This is not the place to review the clotting mechanism but even a simple scheme (Fig. 1) shows clearly the existence of various positive and negative feedback systems. Thrombin activates factors V, VIII and XI but also the APC-system, so that it first enhances its own formation and then inhibits it. Factor Xa activates prothrombin but, via TFPI, inhibits its own activation, etc. Even the end product, fibrin plays a

Correspondence to: Prof. H. C. Hemker, Synapse b.v. Universiteit Maastricht. P.O. Box 616, 6200 MD Maastricht, The Netherlands - Tel. +31433388 1675; Fax: +31433884159; E-mail: C.Hemker@thrombin.com role in the generation of thrombin because it retains active thrombin that is inaccessible to antithrombin and capable of activating factors $\mathrm{V}$, VIII, XI and platelets (7). Moreover there are a number of "minor players" in plasma such as $\beta_{2}$-glycoprotein $1, \alpha_{1}$-antitrypsin, $\alpha_{2}$-macroglobulin, heparin cofactor II, C4b-binding protein, phospholipase $\mathrm{A}_{2}$, vitronectin, TAFI, lactoferrin, glycosaminoglycans etc. that can influence thrombin generation without having a prominent part in the mainstream of the coagulation mechanism.

In the presence of platelets the complications multiply: thrombin and fibrin activate platelets, platelets expose phospholipids and the kinetics of the generation of factor Xa, thrombin and APC are dependent upon the amount, the physical form and the chemical composition of these phospholipids.

This degree of complication has an important consequence: The ensemble of reaction mechanisms is so complex that it is beyond the power of enzyme kinetic analysis. For isolated reactions this problem does not arise. Slightly bigger subsystems can be analysed in terms of "catastrophe theory" (8) and "non linear kinetics" (9) but the complete system defies such approach.

This makes that the reaction of the physiological system is difficult if not impossible - to predict from the knowledge of its isolated parts. Consequently, if we want to know about physiological function we will have to measure it under circumstances that are close to those in vivo; we have, so to speak, to assess the function of the "isolated organ". The choice of the "isolated organ" is a compromise. Going from platelet poor plasma (PPP) to platelet rich plasma (PRP) to whole blood, the system becomes more representative of what happens in the body and technically more difficult to assess.

The recognition of this need for "physiological chemistry" as opposed to biochemical analysis made us switch to studying thrombin generation in plasma 15 years ago. This is not to say that biochemical reconstruction of the "normal" coagulation pathway is not an interesting intellectual exercise, but it should not be considered representative of the complete picture as it occurs in vivo $(10,11)$.

\section{The Thrombogram and How to Measure it}

The last few years have seen a revival of the interest in a timehonoured tool of the clotting trade $(12,13)$ : the thrombin generation curve, or "thrombogram" as we now call it. Here we would like to discuss in how far this test can be expected to reflect the clotting function of blood. (Aside: not to be confused with the "thrombelastogram" which monitors changes in mechanical properties of the developing clot (14).

The general form of the thrombogram is shown in Fig. 2. There may or there may not be a lag-time, then an explosive rise to a peak value is seen and a slow decline follows. A clot forms at the end of the lag time, as soon as the first traces of measurable thrombin are formed. The lag 


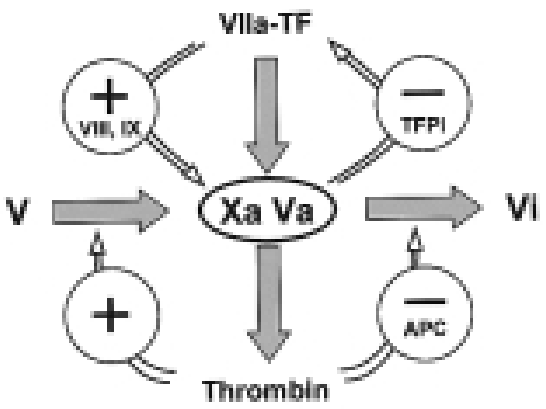

Fig. 1 Feedback mechanisms in tissue factor induced thrombin generation. In this (over)simplified clotting scheme, the vertical axis is the traditional cascade mechanism, the horizontal axis shows the regulation of prothrombin conversion via activation and inactivation of factor $\mathrm{V}$. The same type of regulation governs the alternative factor $\mathrm{X}$ activation, with factor VIII in the role of factor $\mathrm{V}$ and factor IXa in the role of factor Xa (left upper quadrant). Factor Xa binds to tissue factor pathway inhibitor (TFPI) and this complex quenches the factor VIIa-tissue factor complex (right upper quadrant). A third positive feedback, the activation sequence thrombin > factor XI > factor IX has been omitted so as to overload the figure

time therefore, for all practical purposes, equals the clotting time. During the lag time the traces of thrombin are formed that, through feedback activation, cause explosive thrombin formation. In the intrinsic system (aPTT) the rate-limiting positive feedback effect is probably activation of factor VIII. In PRP the exposure of procoagulant phospholipids by the platelet triggers explosive thrombin formation (15). That it is thrombin, rather than other components of the clotting mechanism that are at the basis of feedback activation phenomena can be deduced, among other things, from the inhibitory effects of hirudin $(15,16)$.

Thrombin generation is dependent upon the trigger used. High concentrations of TF start the classical extrinsic pathway. At lower concentrations thrombin generation takes more complicated pathways in which the antihaemophilic factors (VIII, IX and XI) are involved (17-20). Triggering by low amounts of tissue factor is probably the more physiological situation (21), the role of contact activation, i. e. of the classical intrinsic pathway, remains doubtful.

To obtain thrombin generation in PPP procoagulant phospholipids have to be added, in PRP the platelets provide these. Inhibition of platelet function inhibits thrombin generation because it inhibits scrambling of the platelet membrane which makes procoagulant phospholipids available (22).

The use of the thrombogram as a global function test has been severely limited by the technical difficulties in obtaining the curve. The classical subsampling method, as in the experiments in Fig. 2, takes 1-2 $\mathrm{h}$ of two trained people for a series of six curves. The thrombogram can be measured continuously by the use of special substrates (23). These substrates are split slowly, with a velocity that remains proportional to the concentration of thrombin over the whole of the thrombin generation process $(24,25)$. In a suitable laboratory automaton two dozen thrombograms can be recorded simultaneously in this way. The drawback is that the plasma has to be defibrinated in order to prevent turbidity that would disturb optical density registration upon coagulation. This automatically prevents measurements in platelet rich plasma. This problem can be circumvented by using fluorogenic substrates (26).

A technical problem arises from the fact that part of the thrombin in plasma reacts with $\alpha_{2}$-macroglobulin $\left(\alpha_{2} \mathrm{M}\right)$ to form a complex that, though biologically inactive, still is capable to convert small substrates.
Thus, during thrombin generation in vitro, amidolytic activity builds up that is not due to thrombin itself and that has no known biological activity. By a mathematical procedure it is possible to subtract this irrelevant activity and obtain the activity curve of free thrombin only. An excel spreadsheet carrying out this operation is to be found at www: thrombin.com. Recently we found substrates that are split by thrombin but not by the $\alpha_{2} \mathrm{M}$-thrombin complex, which circumvents this problem (unpublished).

\section{The Endogenous Thrombin Potential (ETP)}

A particularly interesting feature of the thrombogram is the area under the curve, i.e. the endogenous thrombin potential or ETP (24). It represents the number of "man-hours" of thrombin that develop, and hence the amount of "enzymatic work" that thrombin is potentially capable to accomplish during its lifetime in clotting blood. In a clotting time measurement this thrombin goes unobserved but in vivo it may diffuse away from the site where blood clots and exert its haemostatic and thrombotic actions in the surrounding area.

We did not as yet encounter an antithrombotic that did not diminish the ETP. The action of all anticoagulants is seen in platelet poor plasma triggered with modest amounts of tissue factor. In platelet rich plasma, the thrombogram additionally renders the action of anti-platelet drugs. This is not meant to question the importance of inhibition of aggregation and adhesion but one surmises that inhibition of thrombin generation contributes to the activity of anti-platelet drugs (27).

The limited use of clotting times is reflected in the thrombogram because there is no fixed relation between the lag-phase ( $\approx$ clotting time) and the area under the curve (= thrombin potential).

The residual amidolytic activity in serum, due to the $\alpha_{2} \mathrm{M}$-thrombin complex, is proportional to the ETP and further dependent upon the level of $\alpha_{2} \mathrm{M}$ and other conditions in the plasma. This property can be used to estimate the influence of addition of thrombomodulin or other inhibitors on the ETP (28). The ratio of the amidolytic end-level with and without an addition is the ratio of the ETPs with and without the addition. This method has been used by Rosing as a sensitive device for measuring changes in APC sensitivity brought about by different types of oral contraceptives $(29,30)$.

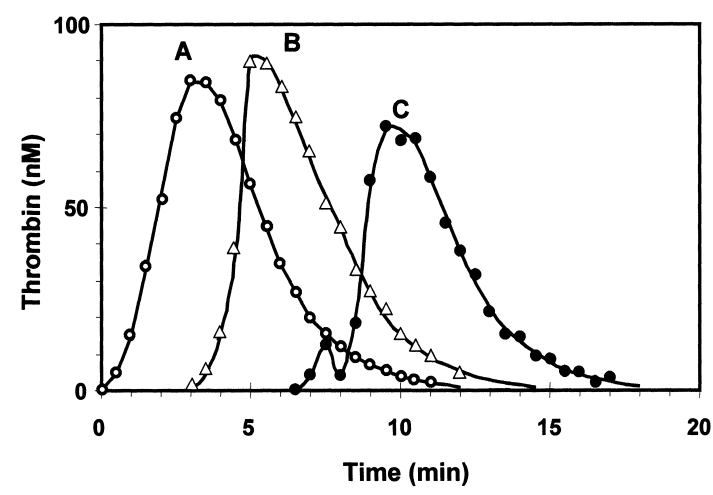

Fig. 2 The Thrombogram. The curves were obtained by subsampling from clotting plasma at $30 \mathrm{~s}$ intervals and measuring the thrombin formed. A) Platelet poor plasma, triggered with a moderate amount of tissue factor, $1 \mu \mathrm{M}$ phospholipids and $\mathrm{Ca}^{++}$. B) Platelet poor plasma triggered by contact activation with kaolin and $\mathrm{Ca}^{++}$, in the presence of $1 \mu \mathrm{M}$ phospholipids. C) Platelet rich plasma triggered by recalcification only 


\section{Results Obtained with the Thrombogram}

We first applied thrombin generation measurement to investigate the mode of action of heparin (31). The thrombogram is the result of simultaneous prothrombin activation and thrombin inactivation. The velocity of thrombin decay can be calculated and therefore also the course of prothrombin conversion. In this way we could demonstrate that heparins, both unfractionated and low molecular weight, act essentially on thrombin decay rather than on prothrombin conversion. This result has not been questioned, neither has it been recognised by those heparin pharmacologists who continue to think in terms of prothrombinase inhibition ("anti-factor Xa activity").

The reconstruction of the time course of prothrombin conversion, together with measurements of factor $\mathrm{Va}$ and $\mathrm{Xa}$ in clotting plasma also allowed to observe that the plasma concentrations of these factors are over ten times those required for prothrombinase formation (16, 32 ). We found that in order to develop $50 \%$ of normal thrombin generation one requires about $2 \%$ factor VII and about $5 \%$ of factors XI, X and $\mathrm{V}$ (33). This is to be expected on basis of the classical work of Owren, Macfarlane and others who observed normalisation of deficient plasmas by only a few \% of normal plasma added (13). It nevertheless continues to surprise (11).

With the automated method it was possible to measure the thrombogram in a number of conditions. It appeared to be increased in congenital prothrombotic states like antithrombin deficiency and prothrombin mutation A20210G (34) as well as in venous and arterial thrombosis (25). In disorders of the APC system the increase is dependent on the conditions of the test. If high concentrations of TF are used and no thrombomodulin is present, the APC system can be short circuited. At intermediate TF, as in our routine procedure (25), a moderate effect is seen ( 10\% increase). At intermediate and low TF in the presence of thrombomodulin the increase can be several fold (28).

The acquired APC resistance brought about by hormonal changes like pregnancy or the use of oral contraceptives merits special attention. It was found that pill-use increases thrombin generation by about $10 \%$ (35). Rosing et al. by applying the $\alpha_{2}$ M-thrombin end point method, showed that this increased thrombin generation could be attributed to an acquired APC-resistance $(29,30)$. The thrombogram plus or minus added APC appeared to be a superior way to quantify APC resistance and was so sensitive as to allow the detection of differences between second and third generation of oral contraceptives. Epidemiologists find more pill-thrombosis with those types of pill that cause the higher increase in the ETP (= area under the thrombogram) (36).

In order to establish the relation between the ETP and the incidence of thrombosis and bleeding under oral anticoagulation, we first determined the relation between INR and ETP in 200 samples from orally anticoagulated patients. Then we re-expressed the results from a 7000 patient-years study in the Dutch thrombosis services (37) in terms of the ETP (Fig. 3). The therapeutic gap appears to be found between 40 and $20 \%$ of the normal ETP. Administration of unfractionated heparin (5000 U subcutaneous) causes 30-40\% inhibition of the ETP until $\sim 5 \mathrm{~h}$ after subcutaneous injection. A low molecular weight heparin (enoxaparin $40 \mathrm{mg}$, subcutaneous) causes 30-70\% of inhibition for at least $8 \mathrm{~h}$ (see also ref. 38). Preliminary results with direct thrombin inhibitors again show that adequate prophylaxis is obtained by inhibition of the ETP to around $40 \%$ of its normal value.

It thus seems that an increase of the ETP to levels of $\geq 110 \%$ of normal indicate a thrombotic tendency and that levels of between 20 and $40 \%$ of normal correspond to adequate antithrombotic treatment. Possibly a stable $20 \%$ decrease over $24 \mathrm{~h}$, such as might be obtained

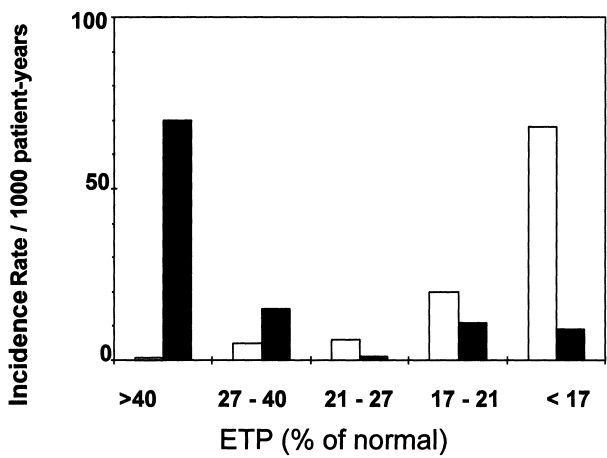

Fig. 3 Incidence of reinfarction (black) and of bleeding (white) as a function of the ETP. This graph is from ref. 37, where the incidence of reinfarction (black columns) or bleeding (white columns) is given as the function of the INR (from left to right: $<2,2-3,3-4,4-5,>5$ ). We established the relation between INR and ETP in 350 patients and replaced the INR boundaries by the equivalent ETP boundaries

with drugs with a favourable pharmacokinetic profile (the antithrombin binding pentasaccharide, oral thrombin inhibitors) will already cause an antithrombotic effect. Aspirin decreases the ETP by about $10 \%$ but, there, inhibition of aggregation will play its role apart from the anticoagulant effect. Inhibition to below $20 \%$ of normal carries the risk of bleeding. In severe deficiency of factors V, VII, VIII, IX or XI we found ETP values $<10 \%$ of normal (unpublished results and ref. 39).

\section{Thrombin Generation and Platelet Function}

Recent research stresses the importance of cross-talk between platelets and the clotting system. For many years studies on blood coagulation have been carried out in platelet free plasma, whereas platelets were studied in non-recalcified- or heparinized plasma. This hardly allows to observe interactions between the cellular and the humoral components of the haemostatic and thrombotic system. Thrombin generation in platelet rich plasma (PRP) does reflect this interaction. Our first experiments in this domain showed that traces of tissue factor, insufficient to provoke thrombin generation in PPP, will start the process in PRP after a lag-time of several minutes (15). During that lag time, traces of thrombin (in the picomolar range) cause the platelets to provide the necessary procoagulant lipids. Thrombin generation in PRP reflects the combined effect of the clotting factors of PPP plus the procoagulant functions of platelets. Thrombin generation in the presence of platelets is the more interesting because the composition and physical form of the procoagulant phospholipids that become available change during the process. This influences the activity of the membrane-borne enzymes of the coagulation mechanism. It is evidently more representative of the in vivo situation to allow the platelets to play their natural role than to add foreign phospholipids.

The peak height and the ETP of the thrombogram of PRP are diminished in Glanzmann's thrombasthenia and upon blocking GPIIb/IIIa (27). In von Willebrands disease these parameters are low as well, which cannot be ascribed to a lack of factor VIII. At least part of this effect is due to adsorption of vWF on formed fibrin and subsequent activation of the platelet via GPIb (40). Clopidogrel (41) and aspirin (42) and in fact many, if not all, platelet inhibitors diminish thrombin generation in PRP (unpublished data). 


\section{Conclusions and Future Developments}

From the above it seems that thrombin generation is a plausible candidate for a test that reflects the phenotype of the coagulation system and its modulations by drugs. It can be studied at different levels. Moving from biochemistry to (patho)physiology we can recognise: 1) the determination of single clotting factors, 2) thrombin generating systems, reconstructed from isolated clotting factors, 3) platelet poor plasma, 4) platelet rich plasma, 5) whole blood. With each step the system becomes more complicated and our analytical understanding decreases. With each step also the system becomes more representative of what is happening in vivo and with each step the information obtained is more relevant from the medical and pharmaceutical point of view.

For the moment the largest subsystem that can be conveniently studied is PRP (26). The technical embodiment as a fluorescence measurement in microtiter plates not only allows multiple experiments to be carried out simultaneously but also, by using plates in which endothelial cells are grown, to investigate elements of vessel wall-platelet interaction.

Thrombin generation in the "isolated organ" blood is an obvious next step. Indeed white and red cells do influence thrombin generation (43). For the moment, blood can be studied only via complicated subsampling techniques (41). An automated technique has been reported, but in our hands it gave a signal that is more dependent upon sedimentation rates of red blood cells than upon thrombin generation (44). Nevertheless we are confident that a solution will be found in the near future. Even with whole blood, the information obtained remains limited however, aberrations of the haemostatic-thrombotic system that are primarily located in the vessel wall will go unrecognised until their effect is transmitted to the blood (45).

A further approach to the situation in vivo would be measuring under conditions of controlled flow and shear stress. Instruments capable to do this are easy to conceive but will certainly require several man-years of development.

The adequate function test of the haemostatic-thrombotic system that we are hoping for will a) recognise blood borne prethrombotic states, b) correlate with the clinically observed bleeding tendency in congenital and acquired disorders, c) indicate the level of anticoagulant treatment independent of the drug used. The data presented here suggest that thrombogram is a candidate for such a test. In how far, in the end, it will indeed fulfil its promise can only be decided on basis of extensive clinical experience that is yet to come.

\section{References}

1. Agnelli G. Thrombin plays a pivotal role in vascular re-occlusion after PTCA and coronary thrombolysis. Cardiovasc Res 1996; 31: 232-4.

2. Badimon L, Meyer BJ, Badimon JJ. Thrombin in arterial thrombosis. Haemostasis 1994; 24: 69-80.

3. Chesebro JH, Rauch U, Fuster V, Badimon JJ. Pathogenesis of thrombosis in coronary artery disease. Haemostasis 1997; 27: 12-8.

4. Fuster VVM. Thrombosis in Cardiovascular Disorders. Philadelphia: W. B. Saunders 1992.

5. A double-blind trial to assess long-term oral anticoagulant therapy in elderly patients after myocardial infarction. Report of the Sixty Plus Reinfarction Study Research Group. Lancet 1980; 2: 989-94.

6. Neri Serneri GG, Rovelli F, Gensini GF, Pirelli S, Carnovali M, Fortini A. Effectiveness of low-dose heparin in prevention of myocardial reinfarction. Lancet 1987; 1: 937-42.
7. Kumar R, Béguin S, Hemker HC. The influence of fibrinogen and fibrin on thrombin generation - evidence for feedback activation of the clotting system by clot bound thrombin. Thromb Haemost 1994; 72: 713-21.

8. Roy AB. Catastrophes and bifurcations in biochemical networks. In: Catastrophe, Theory and Applications. Sinha DK, ed. New York: John Wiley \& sons 1981; 112-9.

9. Selkov EE. Non linearity of multienzyme systems. In: Analysis and simulation of Biochemical Systems. Hemker HC, Hess B, eds. Amsterdam, North Holland: American Elsevier 1972; 145-62.

10. Butenas S, van't Veer C, Mann KG. "Normal" thrombin generation. Blood 1999; 94: 2169-78.

11. Mann KG. How much factor V is enough? Thromb Haemost 2000; 83: 3-4.

12. Seegers WH. A personal perspective on hemostasis and thrombosis (19371981). Semin Thromb Hemost 1981; 7: 177-307.

13. Biggs R, Macfarlane RG. Human Blood Coagulation and its Disorders. Oxford: Blackwell 1953.

14. Hartert HS, J. A. The physical and biological constants of thrombelastography. Biorheology 1962; 1: 31-9.

15. Béguin S, Lindhout T, Hemker HC. The effect of trace amounts of tissue factor on thrombin generation in platelet rich plasma, its inhibition by heparin. Thromb Haemost 1989; 61: 25-9.

16. Pieters J, Lindhout T, Hemker HC. In situ-generated thrombin is the only enzyme that effectively activates factor VIII and factor V in thromboplastin-activated plasma. Blood 1989; 74: 1021-4.

17. Josso F, Prou-Wartelle, O. Interaction of tissue factor and factor VII at the earliest phase of coagulation. Thromb Diath Haemorr 1965; Suppl. 17: 35-44.

18. Osterud B, Rapaport SI. Activation of factor IX by the reaction product of tissue factor and factor VII: additional pathway for initiating blood coagulation. Proc Natl Acad Sci USA 1977; 74: 5260-4.

19. Von dem Borne PA, Bajzar L, Meijers JC, Nesheim ME, Bouma BN. Thrombin-mediated activation of factor XI results in a thrombin-activatable fibrinolysis inhibitor-dependent inhibition of fibrinolysis. J Clin Invest 1997; 99: 2323-7.

20. Cawthern KM, van't Veer C, Lock JB, DiLorenzo ME, Branda RF, Mann KG. Blood coagulation in hemophilia A and hemophilia C. Blood 1998; 91 : 4581-92.

21. Rapaport SI, Rao LV. The tissue factor pathway: how it has become a prima ballerina. Thromb Haemost 1995; 74: 7-17.

22. Bevers EM, Comfurius P, van Rijn JL, Hemker HC, Zwaal RF. Generation of prothrombin-converting activity and the exposure of phosphatidylserine at the outer surface of platelets. Eur J Biochem 1982; 122: 429-36.

23. Rijkers DT, Wielders SJ, Tesser GI, Hemker HC. Design and synthesis of thrombin substrates with modified kinetic parameters. Thromb Res 1995; 79: 491-9.

24. Hemker HC, Wielders S, Kessels H, Béguin S. Continuous registration of thrombin generation in plasma, its use for the determination of the thrombin potential. Thromb Haemost 1993; 70: 617-24.

25. Wielders S, Mukherjee M, Michiels J, Rijkers DT, Cambus JP, Knebel RW, Kakkar V, Hemker HC, Béguin S. The routine determination of the endogenous thrombin potential, first results in different forms of hyper- and hypocoagulability. Thromb Haemost 1997; 77: 629-36.

26. Hemker HC, Giesen PLA, Ramjee M, Wagenvoord R, Béguin S. The thrombogram: monitoring thrombin generation in platelet rich plasma. Thromb Haemost 2000; 83: 589-91.

27. Reverter JC, Béguin S, Kessels H, Kumar R, Hemker HC, Coller BS. Inhibition of platelet-mediated, tissue factor-induced thrombin generation by the mouse/human chimeric 7E3 antibody. Potential implications for the effect of c7E3 Fab treatment on acute thrombosis and "clinical restenosis". J Clin Invest 1996; 98: 863-74.

28. Duchemin J, Pittet JL, Tartary M, Béguin S, Gaussem P, Alhenc-Gelas M, Aiach M. A new assay based on thrombin generation inhibition to detect both protein C and protein S deficiencies in plasma. Thromb Haemost 1994; 71: 331-8. 
29. Rosing J, Tans G, Nicolaes GA, Thomassen MC, van Oerle R, van der Ploeg PM, Heijnen P, Hamulyak K, Hemker HC. Oral contraceptives and venous thrombosis: different sensitivities to activated protein $\mathrm{C}$ in women using second- and third-generation oral contraceptives. $\mathrm{Br} \mathrm{J}$ Haematol 1997; 97: 233-8.

30. Rosing J, Middeldorp S, Curvers J, Christella M, Thomassen LG, Nicolaes GA, Meijers JC, Bouma BN, Buller HR, Prins MH, Tans G. Low-dose oral contraceptives and acquired resistance to activated protein $\mathrm{C}$ : a randomised cross-over study. Lancet 1999; 354: 2036-40.

31. Béguin S, Lindhout T, Hemker HC. The mode of action of heparin in plasma. Thromb Haemost 1988; 60: 457-62.

32. Hemker HC. The mode of action of heparin in plasma. In: Thromb Haemost 1987. Verstraete MV, J.; Lijnen, R.; Arnout, J., ed. Leuven: Leuven University Press 1987; 17-36.

33. Xi M, Béguin S, Hemker HC. The relative importance of the factors II, VII, IX and $\mathrm{X}$ for the prothrombinase activity in plasma of orally anticoagulated patients. Thromb Haemost 1989; 62: 788-91.

34. Kyrle PA, Mannhalter C, Béguin S, Stumpflen A, Hirschl M, Weltermann A, Stain M, Brenner B, Speiser W, Pabinger I, Lechner K, Eichinger S. Clinical studies and thrombin generation in patients homozygous or heterozygous for the G20210A mutation in the prothrombin gene. Arterioscler Thromb Vasc Biol 1998; 18: 1287-91.

35. Rotteveel RC, Roozendaal KJ, Eijsman L, Hemker HC. The influence of oral contraceptives on the time-integral of thrombin generation (thrombin potential). Thromb Haemost 1993; 70: 959-62.

36. Vandenbroucke JP, Helmerhorst FM, Bloemenkamp KW, Rosendaal FR. Third-generation oral contraceptive and deep venous thrombosis: from epidemiologic controversy to new insight in coagulation. Am J Obstet Gynecol 1997; 177: 887-91.

37. Azar AJ, Cannegieter SC, Deckers JW, Briët E, van Bergen PF, Jonker JJ, Rosendaal FR. Optimal intensity of oral anticoagulant therapy after myocardial infarction. J Am Coll Cardiol 1996; 27: 1349-55.
38. Bendetowicz AV, Kai H, Knebel R, Caplain H, Hemker HC, Lindhout T, Béguin $\mathrm{S}$. The effect of subcutaneous injection of unfractionated and low molecular weight heparin on thrombin generation in platelet rich plasma a study in human volunteers. Thromb Haemost 1994; 72: 705-12.

39. Keularts IMLW, Zivellin A, Seligsohn U, Hemker HC, Béguin S. The role of factor $\mathrm{XI}$ in thrombin generation induced by low concentrations of tissue factor. Thromb Haemost 2000; submitted.

40. Béguin S, Kumar R, Keularts I, Seligsohn U, Coller BS, Hemker HC. Fibrin-dependent platelet procoagulant activity requires GPIb receptors and von Willebrand factor. Blood 1999; 93: 564-70.

41. Herault JP, Dol F, Gaich C, Bernat A, Herbert JM. Effect of clopidogrel on thrombin generation in platelet-rich plasma in the rat. Thromb Haemost 1999; 81: 957-60.

42. Kessels H, Béguin S, Andree H, Hemker HC. Measurement of thrombin generation in whole blood - the effect of heparin and aspirin. Thromb Haemost 1994; 72: 78-83.

43. Peyrou V, Lormeau JC, Herault JP, Gaich C, Pfliegger AM, Herbert JM. Contribution of erythrocytes to thrombin generation in whole blood. Thromb Haemost 1999; 81: 400-6.

44. Ramjee MK. The Use of Fluorogenic Substrates to Monitor Thrombin Generation for the Analysis of Plasma and Whole Blood Coagulation. Anal Biochem 2000; 277: 11-8.

45. Bos GM, Rijkers DT, Willems HP, den Heijer M, Béguin S, Gerrits WB, Hemker HC. The elevated risk for venous thrombosis in persons with hyperhomocysteinemia is not reflected by the endogenous thrombin potential. Thromb Haemost 1999; 81: 467-8.

Received April 26, 2000 Accepted after revision May 31, 2000 